\title{
CONSIDERAÇÕES SOBRE A ORGANIZAÇÃO DA PRODUÇÃO LEITEIRA NO ESPAÇO AGRÁRIO BRASILEIRO**
}

\author{
JACOB BINSZTOK* \\ Universidade Federal Fluminense
}

\section{Introdução}

Este trabalho tem por objetivo mostrar as tendências atuais da produção leiteira no espaço agrário brasileiro. A produção está crescendo a uma taxa anual de 5\%, segundo fontes do Governo. O trabalho que estamos desenvolvendo mostra que o segmento agro-industrial (CAI), Parmalat, Nestlé, etc, operando com alto valor agregado, consegue conviver com a produção dos "currais clandestinos", representando cerca de $40 \%$ da produção leiteira do país. Os "currais clandestinos" não estão restritos somente aos pontos mais afastados do espaço agrário brasileiro, mas

\footnotetext{
- Doutor em Geografia Humana. Professor Titular em Geografia Humana do Departamento de Geografia da Universidade Federal Fluminense, Professor do Programa de Pós-Graduação em Geografia.

** Trabalho realizado durante o $1^{\circ} \mathrm{sem} .99$ na Monitoria da disciplina Geografia Agrária. O trabalho teve a participação do monitor Luiz Felipe, e contou ainda com a participação dos discentes Fátima Alves dos Santos e Leonardo Ferreira de Souza.
} 
ao contrário, estão presentes, principalmente na periferia das regiões metropolitanas, como comprovam os casos da cidade de São Paulo e do Rio de Janeiro. A referida produção comercializada "in natura" destina-se ao atendimento dos mercados locais. No caso, os pressupostos da tecnificação parecem não prevalecer, pois trata-se de uma produção de baixo valor agregado, tipicamente de "fundo de quintal”, realizada sem qualquer controle sanitário. O advento de técnicas de controle sanitário, preconizadas pelos grandes empreendimentos empresariais, por certo inviabilizariam a rentabilidade dos "currais clandestinos", mas o que queremos mostrar é uma situação de "convívio" entre os grandes conglomerados multinacionais do leite no Brasil com os denominados "currais clandestinos" pois, numa perspectiva pragmática, tais atores conseguiram capturar suas respectivas fatias no mercado.

A ausência do Estado na regulação do preço do leite e o avanço da produção e do consumo nas últimas décadas, sem a adoção de políticas compensatórias como no Governo Sarney, foram saudadas pelos defensores do livre mercado como importantes marcos para o fortalecimento do setor materno-infantil e conseqüente redução do déficit protéico que atinge comunidades de baixa renda, notadamente nas classes D e E.

A produção de leite, objeto há décadas de programas governamentais específicos, que não conseguiram atender às necessidades de consumo, gerando periódicas crises de abastecimento, obriga o país a recorrer, regularmente, à importação de produtos lácteos, principalmente o leite em pó, com a finalidade de manter uma disponibilidade interna para sustentar as necessidades mínimas da população.

Por último, é importante mencionar as características contraditórias que envolvem a produção de leite, operando ao lado de uma frágil estrutura produtiva primária um complexo agro-industrial de expressivos níveis de modernização econômica e tecnológica.

\section{O constante aumento da produção leiteira}

Apesar da lenta modernização da pecuária leiteira, observamos um constante aumento da produção mantido desde os anos 80, com exceção apenas do período de 1993/1994, marco da estabilização conservadora e da irrestrita abertura para as importações de produtos agrícolas do MERCOSUL. Assim, o acréscimo da produção leiteira no pais é constatado da seguinte forma: 
TABELA 1. EVOLUÇÃO DA PRODUÇÃO DE LEITE NO PAÍS (1980-1990)

\begin{tabular}{lrc}
\hline \multicolumn{3}{c}{ PRODUÇÃO ANUAL DE LEITE NO BRASIL } \\
ANO & PRODUÇÃO EM MIL LITROS & \\
\hline 1980 & 11.162 .245 & $1,44 \%$ \\
1981 & 11.323 .967 & $1,21 \%$ \\
1982 & 11.461 .215 & $0,01 \%$ \\
1983 & 11.463 .018 & $4,09 \%$ \\
1984 & 11.932 .908 & $1,21 \%$ \\
1985 & 12.078 .399 & $3,42 \%$ \\
1986 & 12.491 .809 & $4,04 \%$ \\
1987 & 12.996 .497 & $4,04 \%$ \\
1988 & 13.521 .881 & $4,23 \%$ \\
1989 & 14.094 .857 & $26,27 \%$ \\
TOTAL & 122.526 .785 & \\
\hline
\end{tabular}

Organização: Jacob Binsztok e Luiz Felipe. Coleta: Fátima Alves da Silva Fonte: Censo Agropecuário 1990/95 FIBGE

TABELA 2. EVOLUÇÃO DA PRODUÇÃO DE LEITE NO PAÍS (1990-1995)

\begin{tabular}{|c|c|c|}
\hline \multicolumn{3}{|c|}{ PRODUÇÃO ANUAL DE LEITE NO BRASIL } \\
\hline ANO & PRODUÇÃO EM MIL LITROS & TAXA DE CRESCIMENTO \\
\hline 1990 & 14.484.414 & \\
\hline 1991 & 15.079.187 & $4,10 \%$ \\
\hline 1992 & 15.784 .011 & $4,67 \%$ \\
\hline 1993 & 15.590 .882 & $1,23 \%$ \\
\hline 1994 & 15.783 .557 & $1,23 \%$ \\
\hline 1995 & 16.474 .365 & $4,37 \%$ \\
\hline TOTAL & 93.196 .416 & $13,73 \%$ \\
\hline
\end{tabular}

Organização: Jacob Binsztok e Luiz Felipe. Coleta: Fátima Alves da Silva Fonte: Censo Agropecuário 1990/95 FIBGE

A leitura das informações contidas nas tabelas números 1 e 2 permite verificar que, apesar da redução ocorrida durante a implantação da estabilização conservadora, a produção manteve-se em constantes níveis de crescimento, não se configurando as perspectivas catastróficas referentes à desarticulação e "quebradeira" da produção nacional, em virtude das importações provenientes do MERCOSUL, particularmente da Argentina.

Com o objetivo de melhor compreender o aumento da produção ocorrido na última década, decidimos examinar sua distribuição regional, demonstrada da seguinte forma: 
TABELA 3. DISTRIBUIÇÃO REGIONAL DA PRODUÇÃO DE LEITE NO PAÍS (1980-1989)

\begin{tabular}{llllll}
\hline & & & & & \\
ANO & $\begin{array}{l}\text { REGIÃO } \\
\text { NORTE }\end{array}$ & $\begin{array}{l}\text { REGIÃO } \\
\text { NORDESTE }\end{array}$ & $\begin{array}{l}\text { REGIÃO } \\
\text { SUDESTE }\end{array}$ & $\begin{array}{l}\text { REGIÃO } \\
\text { SUL }\end{array}$ & $\begin{array}{l}\text { REGIÃO } \\
\text { CENTRO } \\
\text { OESTE }\end{array}$ \\
\hline 1980 & 145.145 & 1.568 .707 & 5.668 .797 & 2.571 .598 & 1.208 .088 \\
1981 & 147.376 & 1.513 .058 & 5.903 .755 & 2.594 .822 & 1.164 .956 \\
1982 & 216.248 & 1.424 .458 & 5.960 .462 & 2.657 .183 & 1.202 .863 \\
1983 & 237.113 & 1.244 .251 & 6.123 .389 & 2.563 .953 & 1.294 .312 \\
1984 & 237.754 & 1.447 .929 & 6.163 .462 & 2.624 .991 & 1.422 .770 \\
1985 & 264.306 & 1.575 .003 & 6.094 .835 & 2.667 .802 & 1.476 .453 \\
1986 & 327.549 & 1.695 .403 & 6.100 .544 & 2.807 .405 & 1.460 .408 \\
1987 & 363.252 & 1.647 .453 & 6.580 .331 & 2.862 .791 & 1.542 .670 \\
1988 & 347.862 & 1.786 .964 & 6.690 .698 & 3.089 .827 & 1.606 .530 \\
1989 & 463.057 & 1.965 .291 & 6.806 .661 & 3.240 .272 & 1.616 .571 \\
\hline
\end{tabular}

Organização: Jacob Binsztok e Luiz Felipe. Coleta: Fátima Alves da Silva Fonte: Censo Agropecuário 1990/95 FIBGE

TABELA 4. DISTRIBUIÇÃO REGIONAL DA PRODUÇÃO DE LEITE NO PAÍS (1990-1995)

\begin{tabular}{llllll}
\hline & & & & & \\
ANO & $\begin{array}{l}\text { REGIÃO } \\
\text { NORTE }\end{array}$ & $\begin{array}{l}\text { REGIÃO } \\
\text { NORDESTE }\end{array}$ & $\begin{array}{l}\text { REGIÃO } \\
\text { SUDESTE }\end{array}$ & $\begin{array}{l}\text { REGIÃO } \\
\text { SUL }\end{array}$ & $\begin{array}{l}\text { REGIÃO } \\
\text { CENTRO } \\
\text { OESTE }\end{array}$ \\
\hline 1990 & 555.216 & 2.045 .268 & 6.923 .301 & 3.262 .255 & 1.648 .374 \\
1991 & 684.354 & 2.174 .500 & 6.990 .638 & 3.389 .354 & 1.840 .341 \\
1992 & 725.498 & 2.266 .926 & 7.216 .494 & 3.585 .639 & 1.989 .454 \\
1993 & 715.132 & 1.682 .911 & 7.344 .116 & 3.685 .567 & 2.163 .156 \\
1994 & 651.982 & 1.772 .817 & 7.351 .889 & 3.830 .620 & 2.176 .249 \\
1995 & 706.696 & 1.886 .614 & 7.539 .464 & 4.102 .597 & 2.238 .994 \\
\hline
\end{tabular}

Organização: Jacob Binsztok e Luiz Felipe. Coleta: Fátima Alves da Silva Fonte: Censo Agropecuário 1990/95 FIBGE

A situação da produção leiteira nordestina e do Centro-Oeste pode estar associada a questões históricas do desenvolvimento brasileiro, quando sabemos que o Nordeste está relegado a segundo plano na política agropecuária nacional e que o Centro-Oeste é a mais recente "fronteira agrícola" do país, sendo, também, cenário de um novo padrão de projetos e de pesquisas agrícolas, principalmente no setor de grãos e melhoramento de pastagens, confirmando as tendências enunciadas pelas tabelas $n^{\text {os }} 3$ e 4 , segundo dados do Governo Federal.

Podemos também destacar o papel hegemônico, na produção nacional, das regiões Sudeste e Sul, mantendo-se à frente em relação a outras regiões, e inserindo-se no 
denominado Centro-Sul, que concentra $85 \%$ da produção, refletindo o conflito distributivo existente no país.

Outro dado relevante é que se a produção nacional de leite "in natura", até 1995 (segundo dados oficiais do último Censo Agropecuário 1995/1996), aumentou consideravelmente em termos totais, colocamo-nos no direito de fazer indagações que, provavelmente, poderão ou não ser justificadas pelos órgãos federais, comprometidos com uma política de importações de leite: por que motivos estariam insistindo em manter os níveis de importações de produtos lácteos oriundos, principalmente, da Argentina? Ora, se obtivemos constante aumento da produção leiteira no país, será que não haveria certa flexibilização das autoridades para com o país limítrofe? Tais procedimentos seriam parte apenas de uma estratégia mais ampla, para mantê-lo em nossa esfera de influência econômico-regional, caracterizada pela dependência entre ambos países em termos de trocas comerciais e do MERCOSUL, em particular, no âmbito da produção de leite "in natura"?

\section{As questões do trabalho, Estado e Mercosul}

Uma das formas de atenuar a questão do desemprego no entorno das áreas metropolitanas parece ser a ocupação realizada pelos "currais clandestinos", pois a precarização e a flexibilização das relações trabalhistas têm conduzido a uma pauperização expressiva dos segmentos da classe trabalhadora, ditadas pelo modelo do Estado mínimo. Nesta perspectiva, os "currais clandestinos" podem ser considerados como uma forma de resistência à crescente proletarização, gerando renda fixa para a família e reduzindo custos para os consumidores locais de baixa renda.

Também estão sendo observadas tendências nos assentamentos de Reforma Agrária para a produção de leite, na medida que esta atividade garante ganhos de renda permanente. Neste particular, a produção poderia contribuir com uma significativa redução do déficit protéico, principalmente nas classes $\mathrm{D}$ e $\mathrm{E}$, que possivelmente estariam consumindo mais o produto em decorrência da estabilização conservadora promovida pelo Plano Real.

No decorrer da pesquisa, constatamos que há uma certa concorrência "por baixo", realizada pelos "currais clandestinos" e "por cima", realizada pelas multinacionais. Nesta perspectiva, os produtores intermediários (cooperativas de produção) estariam emparedados, sujeitos a forte concorrência tanto a jusante quanto a montante, já que a tendência dos oligopólios multinacionais é empurrar os atores intermediários para baixo.

Recentemente, em pesquisa de campo no município de Rio Bonito, próximo da Região Metropolitana do Rio de Janeiro, verificamos casos de completa "perversidade" tecnológica, onde produtores manuseavam ordenhas mecânicas em rústicas instalações não azulejadas e de terra batida, não possuindo, portanto, recursos para o melhoramento do rebanho ou das pastagens optando assim pelas operações do padrão 
tecnológico, voltadas diretamente para a redução da mão-de-obra utilizada na pecuária leiteira.

No final dos anos 80/90 percebe-se, nitidamente, a mudança do papel do Estado e, nesta linha, o Estado é concebido sem uma função reguladora, pretendendo-se colocar uma função "fiscalizadora" que ainda não conseguiu ser implantada na forma típica dos modelos preconizados pelo liberalismo político-económico. Um exemplo é o da intervenção que o Estado faz como vigilante sanitário, a fim de pressionar os pequenos e médios produtores, de modo que estes façam cumprir as leis e medidas cabíveis em relação às condições sanitárias dos estabelecimentos rurais e das cooperativas.

A "retirada do Estado" ocorre de forma diferenciada segundo setores e atores envolvidos. Se em termos de política setorial o retrocesso da ação governamental tem sido manifesto no marco de políticas altamente individualizadas, determinados agentes com acesso a locus de poder dentro do Estado (principalmente a Carteira Agrícola do Banco do Brasil ), continuam gozando das benesses do Governo - basta citar, por exemplo, os recursos estatais para manter os níveis de renda de alguns complexos agro-industriais, particularmente o sucro-alcooleiro, em 1993, onde o Banco do Brasil concedeu empréstimos subsidiados no valor de US\$ 1,1 bilhão aos usineiros de açúcar e do álcool.

A "abertura da economia" e o programa de liberalização comercial projetado para o MERCOSUL parecem não apresentar grandes repercussões para a produção de leite "in natura" do país, pois as políticas de ordem macro-econômicas, decididas na área do Ministério da Fazenda, tornam-se determinantes no rumo da agricultura e levando esta à subordinação e dependência quando das decisões a serem tomadas no próprio Ministério da Agricultura.

A meta da estabilidade conservadora, que tem caracterizado os programas econômicos dos últimos governos, tem contribuído para legitimar a subordinação da política agrícola aos imperativos do neoliberalismo; tanto é que, na esfera macro-econômica, abandonaram-se as políticas do nacional-desenvolvimentismo, característica do estado intervencionista até o final dos anos 80.

No âmbito de cada pais, o MERCOSUL tem sido justificado pela necessidade de uma melhor e mais fortalecida participação no processo de intensificação dos fluxos comerciais e financeiros a níveis internacionais, para o qual era necessário formar parte de um bloco de países.

Nesse sentido, o MERCOSUL pode ser visto também como resposta às mudanças ocorridas no cenário internacional. Dentre elas, cabe salientar os processos de regionalização em curso, ou melhor, em primeiro lugar, a consolidação da União Européia; em segundo lugar, a conformação do bloco de países da América do Norte, o NAFTA (North American Free Trade Agreement); e, em terceiro lugar, o bloco asiático, que tendo como eixo o Japão, inclui os chamados "Tigres Asiáticos" e, mais recentemente, a Malásia, Tailândia e Indonésia.

Com a desregulamentação da economia, a promoção das privatizações e a liberalização das importações, montou-se o tripé do receituário neoliberal, inaugurando-se o 
tempo do Estado mínimo, privilegiando-se as questões macroeconômicas e relegando-se as políticas setoriais a um plano secundário.

Se analisarmos a dimensão agropecuária do processo de integração sub-regional, percebemos que o MERCOSUL é parte de um programa de transição para outro modelo agrícola que, entretanto, ainda não conseguiu adquirir contornos definitivos.

As evidências indicam que os complexos agro-industriais e as cooperativas empresariais se converterão em instituições centrais dessa nova fase do processo de modernização da agricultura, participando ativamente no próprio desenho das diretrizes do novo modelo agrícola. Se, tradicionalmente, estas empresas tiveram grande capacidade de influir nas decisões sobre os rumos da agricultura, a chamada privatização do Estado está sendo substituída pela privatização de questões públicas, principalmente nos setores de assistência técnica, extensão rural e de crédito agrícola.

Nesse sentido, são ilustrativos os exemplos desenhados por líderes como a Sadia, Souza Cruz, Nestlé, Parmalat, etc, nos quais se define um tipo de produtor ideal, modelo que deverá ser seguido pelos seus agricultores integrados. O complexo define as características do produto, sua forma integrada e sua organização produtiva de estabelecimento familiar. Pelo poder econômico e político que essas empresas detêm é que suas iniciativas possuem grande influência no espaço agrário brasileiro.

Tratando-se de alimento básico, o leite foi alvo há décadas de programas governamentais específicos, que mantiveram deliberadamente frágil a produção primária, portanto, insuficiente às necessidades de consumo, gerando crises periódicas de abastecimento, convivendo ao lado de uma indústria transformadora expressiva e com razoável desenvolvimento tecnológico. Assim, o país recorre regularmente à importação de produtos lácteos, em especial o leite em pó, para manter uma disponibilidade interna correspondente ao consumo de quantidades mínimas pela população. A participação relativa dos países do MERCOSUL nestas importações elevou-se bastante desde 1989, no bojo da expansão do intercâmbio comercial regional. Assim, em 1999, o país gastou cerca de U\$440 milhões na importação de produtos lácteos, representando 2,40 bilhões de litros, estimando-se a produção nacional em torno de 20 bilhões de litros e o consumo na ordem de 22 bilhões de litros anuais.

$\mathrm{O}$ acesso facilitado aos produtos lácteos argentinos e uruguaios, com vantagens comparativas na produção primária frente aos nacionais, coloca uma primeira questão, a de avaliar a modernização da pecuária leiteira brasileira. Uma segunda questão a ser vista, refere-se às redefinições que a integração provocará nas estratégias, se tais fatos inibirão a indústria de leite e derivados instalada no pais, em especial pela forte presença de empresas multinacionais.

O pouco dinamismo da produção e a reduzida modernização da pecuária leiteira são atribuídos, via de regra, aos preços médios reais pagos aos produtores, que caem tendencialmente desde meados da década de setenta.

As razões desse comportamento não estão no controle governamental em si, no caso, a fixação dos preços pagos aos produtores do leite tipo $\mathrm{C}$. $\mathrm{O}$ fracasso da regulamentação do mercado do leite parece localizar-se na inconsistência dos instrumentos 
básicos de intervenção (preços mínimos e tabelamento), dada a incompatibilidade entre a distribuição da renda nacional e as condições de produção do leite "in natura". $\mathrm{O}$ estimulo à produção deparou-se sempre com os limites do mercado e com a necessidade de atender ao consumo de baixa renda.

\section{Considerações Finais}

O caso do MERCOSUL, propagado como principal inimigo da agropecuária brasileira, parece não se confirmar, pois a produção argentina atua como complemento, não inibindo o desenvolvimento da produção leiteira no espaço agrário brasileiro. Todavia, faz-se necessário que o Governo Federal reveja seus planos para o setor leiteiro, visto que não se pode continuar com importações do produto provenientes da Argentina ou do Uruguai, já que nossa produção, em termos percentuais, cresceu razoavelmente nas últimas décadas, quando então deduzimos que, ou há contradição nos números apresentados pelo crescimento na produção do leite "in natura", ou há interesse para que se mantenham os encargos das importações do leite argentino.

O crescimento do comércio inter-regional nos últimos anos, no caso dos produtos agro-alimentares, consistiu principalmente na ampliação das vendas de produtos argentinos e uruguaios ao Brasil, em parte devido às modificações no mercado internacional que lhes foram desfavoráveis. Isso significa que, para alguns produtos daqueles países, a integração representa a abertura de um mercado alternativo de proporções bastante grandes, como é o brasileiro, onde participam complementarmente à produção nacional.

Na ponta industrial, relembramos os ensinamentos de Kautsky, ao observarmos o oligopólio do "complexo lácteo", com a predominância do capital estrangeiro operando com elevada concentração econômica e tecnológica, recentemente demonstrada pela implantação de embalagens cartonadas, do tipo "longa vida", acelerada a partir dos anos 90, com a estabilização conservadora promovida pelo Plano Real, reduzindo sobremaneira a comercialização do leite acondicionado pelas cooperativas em sacos plásticos e majorando em quase $80 \%$ (oitenta por cento) o preço final do produto.

Apresentando um grau médio de concentração em torno de $34 \%$, a presença do capital estrangeiro na indústria de lácteos está em expansão, como comprova a recente aquisição da Vigor pela cooperativa neozelandesa New Zeland Dairy Board, cooperativa detentora de $31 \%$ do mercado internacional de lácteos, perdendo apenas para a União Européia (39\%). No entanto, as contradições do desenvolvimento capitalista na produção leiteira, representadas pelos grandes números de produtores informais e pela presença dos importados, talvez consiga frear um pouco a concentração da indústria de lácteos. No entanto, o quadro de fusões e aquisições parece ser irreversível no atual estágio do desenvolvimento capitalista, e os prejuízos causados aos produtores pela perda do poder da negociação devem ser monitorados pelos órgãos públicos de defesa da concorrência. 
Tendo em vista principalmente a análise de informações censitárias, de observações de campo e consultas bibliográficas, conseguimos estabelecer, ainda, que de forma preliminar, algumas tendências, para a produção de leite no espaço agrário brasileiro observadas na Tabela 5, que podem ser assim explicitadas:

- A produção de leite, estimada em 20 bilhões de litros anuais, apesar dos episódicos enfrentamentos ocorridos no âmbito do MERCOSUL, apresenta hoje um incremento na ordem de $4 \%$ ao ano, inserindo-se em linhas gerais nos padrões contraditórios e desiguais ditados pelo desenvolvimento capitalista no espaço agrário brasileiro.

- Nesta perspectiva, ressaltamos a presença de multinacionais do tipo Nestlé e Parmalat, ao lado de Cooperativas Centrais, Regionais e Locais, operando os clássicos procedimentos de apropriação da renda da terra, explorando o sobretrabalho executado por pequenos e médios produtores, posseiros e, mais recentemente, assentados do MST, que optaram pela pecuária leiteira como um instrumento de obter rendimentos fixos, que atenuem os longos períodos de manutenção dos investimentos realizados na agricultura.

- Na linha das contradições, é importante destacar, ainda, a presença de um grande número de produtores totalmente precarizados, localizados principalmente em áreas próximas às Grandes Regiões Metropolitanas, responsáveis pela produção de 8 bilhões de litros anuais, representando $40 \%$ do total, avaliado em 3,8 bilhões de reais. Ao contrário dos demais produtores, o referido segmento não se encontra monopolizado pelo capital industrial, pois, percebendo sua inviabilidade econômica pelo não atendimento dos requisitos ditados pela vigilância sanitária, aproveitou-se dos seus reduzidos custos para infiltrar-se no abastecimento do produto "in natura" e derivados dos moradores de baixa renda, residentes na periferia dos grandes centros urbanos do país. A criação de uma rede de proteção aos "currais clandestinos" é uma necessidade sócio-econômica, visando dar voz aos microprodutores, na medida em que o atual modelo parece, ainda, não ter se completado, estando, portanto, em transição e com limites não bem definidos. Seria possível resgatá-los para um determinado padrão de qualidade, fora dos parâmetros sanitários preconizados pelos agentes do Estado e das multinacionais?

- Os desequilíbrios regionais da produção leiteira no país podem se ressaltados quando, ao examinarmos as informações contidas na Tabela 4, constatamos o seguinte quadro: o avanço na produção no Centro-Oeste, principalmente nos estados de Goiás ( $2^{\circ}$ produtor nacional) e Mato Grosso do Sul, motivado em parte pela redução de custos, decorrente da política de fomentos creditícios do BNDES e da concessão de isenção e dilatação de prazos para o recolhimento do ICMS; prosseguindo, notamos que a produção da Região Sul, liderada pelos estados do Rio Grande do Sul e Paraná, apresenta-se praticamente estabilizada, enquanto que a do Sudeste mostra a grande supremacia de Minas Gerais ( $1^{\circ}$ produtor nacional). 
TABELA 5. DISTRIBUIÇÃO REGIONAL DA PRODUÇÃO DE LEITE (1995-1998)

\begin{tabular}{|c|c|c|c|c|c|}
\hline Região/Estado & 1995 & 1996 & 1997 & 1998 & $\%$ de partic. \\
\hline \multicolumn{6}{|l|}{ Norte } \\
\hline RO & 202.189 & 241.851 & 280.547 & 288.964 & 1.32 \\
\hline$A C$ & 29.696 & 29.105 & 29.687 & 30.281 & 0.15 \\
\hline AM & 48.977 & 53.140 & 56.860 & 55.723 & 0.28 \\
\hline $\mathbf{R R}$ & 11.210 & 10.764 & 10.979 & 9.881 & 0.06 \\
\hline PA & 308.184 & 319.304 & 328.883 & 309.150 & 1.65 \\
\hline AP & 2.710 & 2.886 & 3.030 & 2.758 & 0.01 \\
\hline TO & 103.731 & 112.272 & 121.254 & 112.766 & 0.59 \\
\hline Total & 706.697 & 769.322 & 831.241 & 809.522 & 4.06 \\
\hline \multicolumn{6}{|l|}{ Nordeste } \\
\hline MA & 145.109 & 149.910 & 154.407 & 149.775 & 0.78 \\
\hline PI & 55.588 & 59.650 & 63.229 & 63.861 & 0.32 \\
\hline CE & 292.346 & 319.434 & 335.406 & 318.635 & 1.65 \\
\hline RN & 105.608 & 120.695 & 131.558 & 123.664 & 0.63 \\
\hline PB & 140.018 & 157.571 & 174.904 & 173.155 & 0.84 \\
\hline PE & 212.709 & 215.776 & 217.934 & 209.216 & 1.12 \\
\hline $\mathbf{A L}$ & 201.077 & 213.179 & 223.838 & 212.646 & 1.11 \\
\hline SE & 66.013 & 65.141 & 64.490 & 59.975 & 0.33 \\
\hline BA & 668.147 & 708.624 & 765.314 & 772.967 & 3.80 \\
\hline Total & 1.886 .614 & 2.009 .980 & 2. 131.079 & 2.083 .895 & 7.86 \\
\hline \multicolumn{6}{|l|}{ Sudeste } \\
\hline MG & 4.762 .543 & 5.537 .089 & 5.758 .573 & 5.700 .987 & 27.55 \\
\hline ES & 362.696 & 377.204 & 384.748 & 373.206 & 1.95 \\
\hline RJ & 432.381 & 510.931 & 551.805 & 540.769 & 2.67 \\
\hline SP & 1.981 .844 & 2.168 .612 & 2.277 .043 & 2.208 .731 & 11.38 \\
\hline Total & 7.539 .464 & 8.593 .836 & 8.972 .169 & 8.823 .693 & 44.86 \\
\hline \multicolumn{6}{|l|}{ Sul } \\
\hline PR & 1.576 .541 & 1.813 .022 & 2.012 .454 & 1.931 .956 & 9.57 \\
\hline SC & 815.379 & 896.917 & 941.763 & 951.180 & 4.70 \\
\hline RS & 1.710 .677 & 2.057 .162 & 2.262 .878 & 2.194 .992 & 10.83 \\
\hline Total & 4.102 .597 & 4.767 .101 & 5.217 .095 & 5.078 .129 & 25.10 \\
\hline \multicolumn{6}{|l|}{ Centro Oeste } \\
\hline MS & 454.743 & 495.670 & 525.410 & 530.664 & 2.62 \\
\hline MT & 307.426 & 328.946 & 348.683 & 352.170 & 1.74 \\
\hline GO & 1.450 .158 & 2.032 .988 & 2.297 .276 & 2.377 .681 & 10.87 \\
\hline DF & 26.667 & 29.334 & 30.801 & 31.417 & 0.15 \\
\hline Total & 2.238 .994 & 2.886 .938 & 3.202 .170 & 3.291 .932 & 15.39 \\
\hline Total geral & 16.474 .366 & 19.027.177 & 20.353 .754 & 20.087 .171 & 97.27 \\
\hline
\end{tabular}

Organização: Jacob Binsztok. Coleta: Leonardo F. de Souza

Fontes: Censo Agropecuário 1980/1995 - FIBGE FNP Consultoria \& Comércio (estimativa) 1996/1998. 
- Por último, é relevante assinalar que os oligopólios dedicados à industrialização do leite (Parmalat, Nestlé, etc.) operam com elevadas margens de lucro, adquirindo o litro do produto ao preço de $\mathrm{R} \$ 0,28$ a $\mathrm{R} \$ 0,32$, sendo comercializados no varejo a $\mathrm{R} \$ 1,00 / \mathrm{R} \$ 1,20$, nos cartonados do tipo "longa vida". Assim, ficam confirmadas as teses de Ariovaldo Umbelino de Oliveira e José de Souza Martins que, entre outros, ressaltaram a questão da exploração e não expropriação dos pequenos e médios produtores na expansão do desenvolvimento capitalista no campo brasileiro. No caso, também, não comprovamos as hipóteses dos neoclássicos sobre os possíveis ganhos obtidos pelos consumidores com a economia de escala e o refinamento tecnológico, pois os oligopólios, livres de qualquer tipo de concorrência, não necessitam reduzir suas elevadas margens de lucro em benefício da ponta consumidora.

\section{A PRODUÇÃO LEITEIRA NO ESPAÇO BRASILEIRO}

Resumo: O trabalho investiga as tendências nacionais e regionais da produção leiteira no país. Segundo os dados censitários, nas últimas décadas, a produção manteve um constante crescimento, estando estimado atualmente em 20 bilhões de litros anuais. O caso do MERCOSUL, propagado como principal inimigo da produção brasileira, parece não se confirmar integralmente, pois a produção argentina atuaria como complemento no crescimento da produção leiteira no país. A nível regional registramos aumento e concentração da produção no Centro Sul e descenso no Nordeste do país.

Palavras-chaves: Produção de Leite, Espaço Agrário.

\section{MILK PRODUCTION IN BRAZILIAN SPACE}

Summary: The work investigates both national and regional tendencies of the milk production in Brazil. According per census data, the production kept a constant increase in the last decade being estimated at 20 billions of liters per year. The MERCOSUL protection, reported as the main enemy of the Brazilian production, seems not totally confirmed as the Argentinian products act as a complement not restricting the growth of the milk production in the country. At a regional level we could register an increase and concentration of the production on the Center-South and a decrease in Northeast of the country.

Keywords: Milk Production, Agrarian Space.

\section{BIBLIOGRAFIA}

BINSZTOCK, J. (1998): “Currais clandestinos”, multinacionais e Mercosul na organização da produção leiteira no espaço agrário. Niterói, $2^{\circ}$ sem. Cadernos do Departamento de Geografia.

LANDIM, Rachel. (2000): Bacia leiteira avança para a região Centro-Oeste do país. Valor Econômico. 25 maio. Caderno Agronegócios.

Vigor começará a produzir margarina e maionese. Valor Econômico. 6-8 out. 2000. Caderno Agronegócios. 
MALUF, Renato. Org. (1993): Mercosul, integração na América Latina e relações com a Comunidade Européia. São Paulo: Ed. DESEP.

OLIVEIRA, Ariovaldo U. O modo de produção capitalista na agricultura. São Paulo: Ática.

RELATÓRIO de pesquisa sobre estudo de caso sobre a produção leiteira na região metropolitana do Rio de Janeiro. (1999): Niterói, UFF, Departamento de Geografia. 